\title{
Postscript: Plurifunctional narratives
}

\author{
JOHN B. HAVILAND
}

\section{Introduction}

In this brief postscript I reflect on these stimulating papers, starting with hopefully well-accepted general precepts, and then commenting on shared themes, from the nature of narrative entextualizations as objects to the interactive social engagements from which they emerge.

Linguistic anthropology and the comparative study of talk-ininteraction take as axiomatic the plurifunctionality of utterances, which always operate on formally laminated but analytically distinct levels to perform multiple sorts of communicative and sociocultural actions. Furthermore, metapragmatics - a metatheory of what we can do with talkinvolves everything from highly regimented, explicit, and available phenomena to problematic, difficult, and largely invisible sorts of action (Silverstein 1981), frustrating the search for definitional precision when comparing folk metapragmatic concepts. Two corollaries follow: that a complex layering of biographical and ethnographic background is required even to identify an interactive fragment as a member of some metapragmatic category (such as 'narrative') in the first place; and that all communicative 'moves' are interactively negotiated and emergent.

First a complaint: utterances are not only multifunctional, but also multimodal. In these for the most part audio-only narrative studies, with data usually in English or presented in free English gloss, one often feels that formal interactive elements may be rendered invisible by design. Ochs (1979) pointed out decades ago that when our data are reduced to the transcripts we use, we must be especially careful how we choose to transcribe. Is there only one possible standard of transcriptional detail? Does the original language matter? Can we somehow read the Italian through an English gloss? Or interpret significant visible action through a desultory textual paraphrase? In introductory linguistics, one hammers home the dictum: 'form first!' ${ }^{1}$ Formal marks of a genre or an activity are only available for scrutiny if communicative form is taken seriously. Fasulo

1860-7330/08/0028-0443

Online 1860-7349

(C) Walter de Gruyter
Text \& Talk 28-3 (2008), pp. 443-451 DOI 10.1515/TEXT.2008.021 


\section{John B. Haviland}

and Zucchermaglio analyze genres via, for example, precise characterization of Italian verbs. Johnson identifies epistemic moves from the varieties of English modals that appear in her police interviews. Johnson also shows, with careful analysis of phraseology, how police interviewers relexicalize 'start-point narratives' into 'formal evidentiary narratives' to incorporate desired perspectives and evaluation. With respect to multimodality, only Bamberg and Georgakopoulou's transcript explicitly includes visible action as part of the narrative record - and necessarily so since gestures, movements, and facial expressions are central metadiscursive mechanisms for managing interaction and voicing interlocutors in their material.

\section{Definitional and typological issues}

All of the studies here seek in one way or another to expand the definition of narrative, but one wonders in the end what sort of category 'narrative' is meant to be, especially across contexts and communicative traditions. Is it a native category (as suggested by Bamberg and Georgakopoulou's [this issue] criterion: '[when] the participants themselves orient to what is going on as a story'-however, pretheoretically or ethnographically, we are to understand 'story')? Does it rely on vestiges of Labov's structural elements - temporal ordering of clauses, complicating actions, or evaluative components, perhaps?' ${ }^{2}$ Must narratives be 'tellable'-a distinctly context-dependent and presumably culturally variable notion? For Fasulo and Zucchermaglio temporal displacement is central, the exploitation of 'the there and then', so that narratives can provide for the telling of unknown, imagined, or at least 'not fully known' events. Bamberg and Georgakopoulou's (this issue) further elaboration of 'fleeting moments of a "narrative orientation" in interactions' (e.g., hinting that there is a story to tell but withholding it) is helpful in showing how a native's perspective might help identify narratives, but this formulation returns us to interactive and ethnographic matters that are systematically excised from many of the transcripts.

For most of these papers, definitions seem less important than typologies of a taken-for-granted 'narrative' category. But the typologies, too, are diverse. Thus, Bamberg and Georgakopoulou's 'atypical' or 'small' stories are identified by suspending as criterial certain discursive characteristics they may lack: full development or coherence, for example. De Fina contrasts 'self-' and 'other-narratives' (which have different interactive and indexical properties) and expands her scope to what she calls 'narrative activity' (one among many 'symbolic practices' with 'their own 
roles and modes of speaking' [citing Gaik]). Still, in the end, she proposes a fairly simple topic-based typology, contrasting with the sequential (Bercelli, Rossano, and Viaro, for example) or functional (e.g., Kjaerbeck; Fasulo and Zucchermaglio) typologies proposed in other papers. As distasteful as fixed definitions or coordinated typologies may be, without some guidelines it seems hard to be sure that we are studying the same things let alone a unified domain.

\section{Contexts of emerging narration}

A strength of this collection is the variety of activities from which the data are drawn: psychotherapy sessions, parent-teacher conferences, police interviews, workplace planning and post-mortem sessions, and dinner conversation at a social club. The studies thus not only problematize canonical elicited narratives but also implicitly challenge the analytic notion of unmarked 'ordinary conversation'. Narratives here emerge from interlocutors' own concerns, but concerns that grow out of situated activities each with characteristic interactive and social configurations. Stories are 'embedded within' (Fasulo and Zucchermaglio) other sorts of discourse, and this wider discourse context thus becomes a central analytic object to understand the genesis in interaction of storytelling, retelling, reworking, and suppression. Moreover, as Kjaerbeck makes explicit, narratives project their discursive contexts in the familiar dual way of all indexical signs: they can both presuppose a certain sort of situation, and they can creatively refashion the context in their wake. So instead of the highly naturalized (or perhaps invisible) motives behind a Labovian narration, we see that stories emerge neither 'naturally' nor 'neutrally'. De Fina has perhaps the most seemingly neutral case: narrative as construction of self (getting to know each other, self-presentation, identity creation), but already highly constrained to certain sorts of selves relevant to an Italian American social club. As most of the authors point out, there need be no particular complicating action in these stories, no risk of a dismissive 'so what?' reaction. Indeed, Johnson argues that suspect narratives before a police interviewer are designed to emphasize the normalcy of narrated events, to minimize the exceptional (and hopefully the culpable as well). Nor need the narrative motives be the same for teller and hearer; in fact, again as in the police interview case, their interests in narratives may be diametrically opposed, a point to which I return at the end of this postscript.

Several papers usefully link context and activity together via the concept of 'community of practice', which implies mutually monitored com- 
municative routines and practices, with an associated social history, and evolving interactive negotiation of community-specific forms and rules of use over time. Such a notion is explicit in Marra and Holmes' analysis of Māori organizational talk and in De Fina's social club, presupposable in the workplace interactions of Fasulo and Zucchermaglio, and presumably applicable as well to Bercelli, Rossano, and Viaro's therapy sessions, or Kjaerbeck's parent-teacher conferences, presumably mini-communitiesof-practice in the making. It is also the wider community of practice (here, one imagines, the British justice system) that gives meaning to the otherwise inexplicit notions of 'precision', 'evidentiality', and 'formality' as applied to narratives in J's police interviews. De Fina also locates some story genres in specific kinds of 'interactional work' (for example, on Italian 'origins'): subpractices, from a wider repertoire, that set up specific argumentative possibilities to which mini-narratives can connect.

Finally, the emphasis on therapy, counseling, and workplace collaboration reminds us of the overall practical context of this work, and the relations between the research questions we ask and the circumstances and activities of the interested participants on whom we rely for data. Narrative studies are thus made consequential to the real world.

\section{Narrative plurifunctionality}

In a much quoted passage, Bauman (1986: 5) writes 'events are not the external raw materials out of which narratives are constructed, but rather the reverse: Events are abstractions from narrative. It is the structures of signification in narrative that give coherence to events in our understanding'. He goes on to caution that narrative 'may also be an instrument for obscuring, hedging, confusing, exploring, or questioning what went on, that is, for keeping the coherence or comprehensibility of narrated events open to question'. As several papers here point out, canonical narratives from this perspective share a kind of event-crystallizing (or questioning), hypothetical, 'subjunctivizing' (Fasulo and Zucchermaglio, citing Bruner) or 'preconstructional' (if not instructional) function with myths and 'justso stories', but also with conjectural problem solving, Ochs et al.'s (1992) 'family detective stories', or Fasulo and Zucchermaglio's 'fictions'. That is, they bring events and situations into existence in some 'possible world'. They involve both a lamination and a (de)calibration of different such worlds, including narrated worlds and narrating worlds. Such creative binding and mutual projection of distinct worlds is the narrative function common to these papers, though often through the reverse formulation: that narratives present alternative perspectives on the same 'events'. 
(Note for example Fasulo and Zucchermaglio's concept of the 'reorganization of knowledge' via narrative as part of the reworking of 'events', both intersubjectively known and knowable after the fact.)

Although with varying sophistication about the notion of 'identity', several papers also highlight 'identity work' (Bamberg and Georgakopoulou) or 'identity construction' (Marra and Holmes) in narrative interactions. ${ }^{3}$ Partly this is a corollary of the inherent indexicality of all utterances - most prominently co-constructed utterances - which always project aspects of interlocutors' manifold 'identities'. Partly it is a matter of referentially explicit 'identification'-self-consciously performing Māori or Italian or professional selves, for example. Partly it is a matter of footing, inhabiting shifting and fragmentable participation frames, as with Bamberg and Georgakopoulou's ten-year-olds.

For me, more problematic are aspects of interpersonal stance management that one might want to link to projected selves. For example, I find 'agreement' and 'disagreement' difficult a priori categories. One cannot reify performance into attitudes or beliefs: stances are more complex than that. So can you read off 'cultural values' directly from conversational moves, pace Marra and Holmes? (And what are the criteria, for example, for recognizing irony and thus shifting the valence of such expressed 'values'?) By contrast, Fasulo and Zucchermaglio's attention to pronoun shifts and footing changes in 'Templates' highlights the intersubjective work always being done in conversation, more complex than just agreement and disagreement. Kjaerbeck (this issue) convincingly writes that '[n]arrative accounts are descriptions that are produced because of a local need in the interaction, and they perform different types of actions, e.g., an explanation, a justification, an excuse'. But, as Austin's (1961) classic paper on excuses is at pains to point out, we need 'clean tools' (lexically and conceptually) to be able to identify such 'types of actions' with confidence in ethnographically varied discourse.

\section{Participant frameworks, voicing, asymmetry}

A similar difficulty for me surrounds notions of 'implicitness' and 'indirection' (part of Marra and Holmes's characterization of Māori interactive style), since such notions are highly dependent on participant structures, which will be my final theme.

Bamberg and Georgakopoulou explicitly take up Goffman's (1979) deconstruction of Speaker, but interestingly the other contributions are less explicit; nor do they engage Goffman's more schematic but important remarks about Hearer. All of the authors here seem to agree that narratives 
are interactive co-productions, 'interactive achievements' by tellers and recipients (categories which deserve further scrutiny). Fasulo and Zucchermaglio appropriately link this co-production to 'distributed cognition' through the 'back and forth movements' of tellership and recipience. However, just as Irvine (1996) productively recast Goffman's decomposition of Speaker into different component roles as reflecting a diachrony of (possibly virtual) 'shadow conversations', part of the complexity about authorship of a story is a function of the social history of particular narratives and the concomitant Bakhtinian revoicing that accompanies cycles of narrative tellings and reworkings. This is especially true in the institutional contexts treated in these papers, which require tellings and retellings fitted to the interactive requisites of successive moments (crime scene, later interview, lawyer's discourses, court; or therapeutic revelation, reworking by therapist, evaluation and hopefully acceptance by therapee, etc.).

Indeed, one way of understanding the relationship between what De Fina invokes as the 'macro' and the 'micro' is as a diachronic engagement between different participant structures. The overall social background to any interaction is itself a kind of macro-participation frame. Here occur the discursive lives of both corroborative or hegemonic 'master narratives' - part of what Marra and Holmes may mean by 'culture' and which may be difficult if not impossible to resist-along with insurrectionist 'templates'. These may be 'shadow' narratives in Irvine's sense, since they are often only available by allusion, as in Bamberg and Georgakopoulou's Shaggy-dog story whose whole point is (a way of) telling (or not telling) about maleness, sexuality, and denial.

Resonances between 'macro' participation frames and those of the interaction at hand endow particular interlocutors with differential authority, power, and what Johnson calls 'interactional resources'. Johnson's Bakhtinian 'superaddressee' in the police interviews, for example - the judges, the courts, and the justice system in general-sits as a brooding presence behind the interviewer and interviewee exchanges. (Compare what Grice 1975 has to say about the 'cooperative principle'.)

Reference to macro structures also gives authority, expertise, and professionalism to the voices of therapists, teachers, supervisors, lawyers, and policemen. In most of the cases considered here, there is a built-in asymmetry of interpretive authority in the reconstruction of events through narrative: therapists, teachers, etc., have first claim at interpretation, though there may be insurrection. (Note that the asymmetry may be subtly altered by different individual skills: some police interviewers are 'better' than others, Johnson tells us, as presumably are therapists, teachers, supervisors, etc., whose authoritative positions may inject themselves in different ways on narrative construals and reshapings.) 
The asymmetries are not only about authoritative voice, but about access and interactive power. Bamberg and Georgakopoulou mention the special sense in which self-stories are often taken as direct mirrors of teller's subjectivities, because of their nonshared nature and the unique access that teller's are meant to have to their own experiences. Bercelli, Rossano, and Viaro's therapists, however, seem not to concede such uniqueness. Bamberg and Georgakopoulou also highlight a different kind of asymmetry, where a (potential) teller makes a (potential) story all the more interactionally 'tellable' by withholding it. This kind of management of 'interactional engagement' is another little considered aspect of narration as activity.

However, the most striking asymmetries here have to do with raw power, nowhere more apparent than in Johnson's study of police interrogations and the professional transformation of narratives to meet institutional requisites. She contrasts two potentially conflicting desiderataprotecting the interests of suspects, versus serving 'justice' - and we could generalize this opposition to most of the institutional contexts examined in these essays: who has the right to tell one's own story? (And when is a story really one's own, anyway?)

The sad fact, however, is that the balance of interactional power is clearly stacked against some narrators from the start. Therapists are meant to do therapy, so clients either acquiesce or buy the services of another. Parents are systematically at the mercy of the 'professional' interpretations of their children's keepers. Institutional settings filter narrative interpretations - stories in the Māori business are 'heard' as about Māori values, or in the Italian American club as about claims to Italianness. And police interviewers are clearly expert at overcoming even the legal protections supposedly allowed to suspects in interrogation, as the suspect's talk in the face of the legal 'right to remain silent' in Johnson's paper shows. This is an institutionalized asymmetry of power. Worse still, Johnson shows clearly that selective silence is, at the least, a poor 'narrative strategy' for suspects, part of the systematic disadvantaging of witnesses in Anglo-Saxon courts, where only 'expert witnesses' are given any leeway in their own testimony, and 'hostile witnesses' can be silenced into accepting other-narration. With respect to culpability and evidence, the interactive shaping of narrative often appears to be a kind of blatant coercion, especially obvious in police interviews - for example, with systematically devoiced undocumented indigenous Mexicans in some of my own recent work (Haviland 2003, 2005), as well, for example, in the asylum interviews studied by Blommaert (2001) or Jacquemet (2005).

In sum, these essays locate narrative texts firmly in the interactive activities in which interlocutors co-create them. They go on to explore 
a great variety of reasons why those same interactants - as well as analysts - may extract narratives, rework them, exhibit them, classify them, contest them, or perhaps even suppress them as part of ongoing interactional work. The move from narration to narrating-from object to process, and from structure to activity-reinforces a shared sense that one must learn how, why, and with whom one can and sometimes must tell stories.

\section{Notes}

1. Which of course does not mean 'form last'.

2. And recall that for Labov narratives were in some sense beside the point, since the 'fear of death story' technique was originally devised to divert speakers' attention to what they were saying and away from how they were saying it.

3. Any illusion that identities can be discrete and monolithic is belied by the ever-shifting stances in the rich materials presented here, characterized as 'performances' of identity. As Bamberg and Georgakopoulou (this issue) write, "constructions of self and identity [are] necessarily dialogical and relational, fashioned and refashioned in local interactive practices'.

\section{References}

Austin, J. L. (1961). A plea for excuses. In Philosophical Papers, 175-204. London: Oxford University Press.

Bauman, R. (1986). Story, Performance and Event: Contextual Studies of Oral Narrative. New York: Cambridge University Press.

Blommaert, J. (2001). Investigating narrative inequality: African asylum seekers' stories in Belgium. Discourse and Society 12 (4): 413-449.

Goffman, E. (1979). Footing. Semiotica 25 (1/2): 1-29.

Grice, H. P. (1975). Logic and conversation. In Syntax and Semantics 3: Speech Acts, P. Cole and J. Morgan (eds.), 41-58. New York: Academic Press.

Haviland, J. B. (2003). Ideologies of language: Some reflections on language and U.S. law. American Anthropologist 105 (4): 764-774.

Haviland, J. B. (2005). Dreams of blood: Zinacantecs in Oregon. In Dislocations/ Relocations: Narratives of Displacement, M. Baynham and A. De Fina (eds.), 91-127. Manchester: St. Jerome.

Irvine, J. T. (1996). Shadow conversations: The indeterminacy of participant roles. In Natural Histories of Discourse, M. Silverstein and G. Urban (eds.), 131-159. Chicago: University of Chicago Press.

Jacquemet, M. (2005). The registration interview: Restricting refugees' narrative performances. In Dislocations/Relocations: Narratives of Displacement, M. Baynham and A. De Fina (eds.), 194-216. Manchester: St. Jerome.

Ochs, E. (1979). Transcription as theory. In Developmental Pragmatics, E. Ochs and B. Schieffelin (eds.), 43-72. New York: Academic Press. 


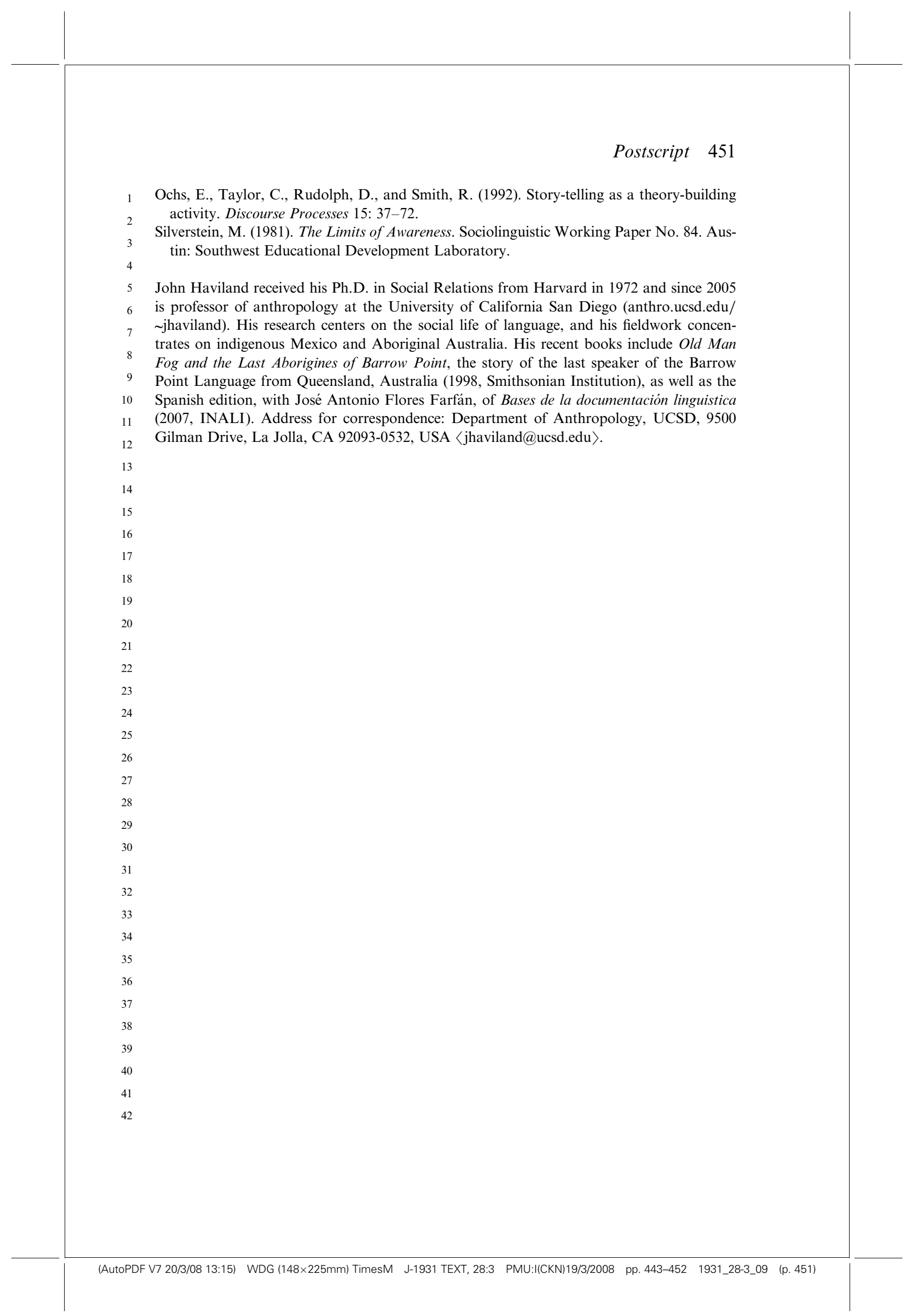




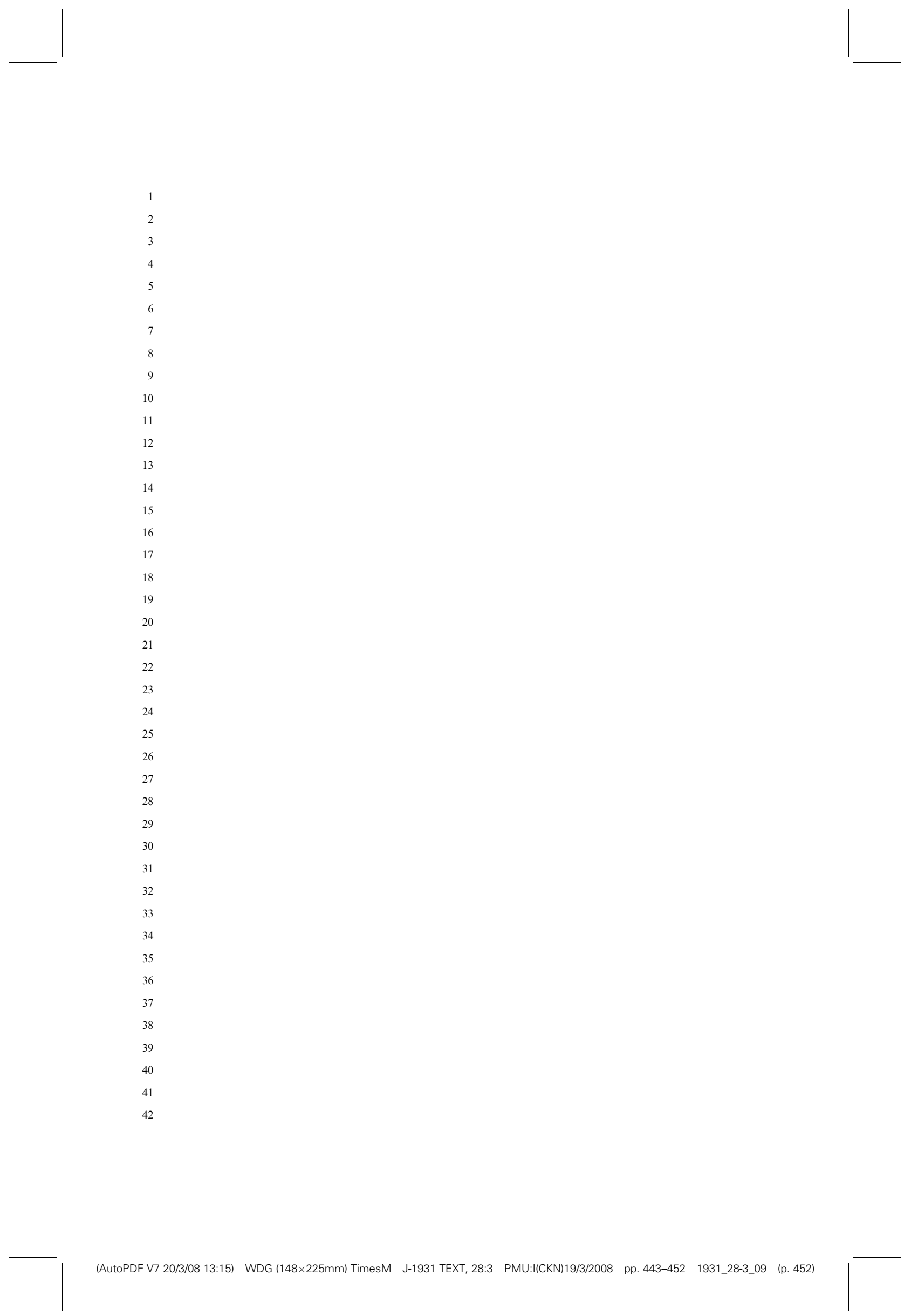

